\title{
HOX Genes and Oncogenesis
}

\section{Alfredo Procino*}

Department of Neurosciences, Reproductive Sciences, Odontostomatologic Sciences and Maxilofacials, University "Federico II" of Naples Odontoiatric School, Italy *Corresponding author: Alfredo Procino, Department of Neurosciences, Reproductive Sciences, Odontostomatologic Sciences and Maxilofacials, University "Federico II" of Naples Odontoiatric School, Italy, Tel: 0817462080; Fax: 0817462080; E-mail: alfredo.procino@unina.it

Received date: May 18, 2014; Accepted date: October 8, 2014; Published date: October 15, 2014

Copyright: (c) 2014 Procino A. This is an open-access article distributed under the terms of the Creative Commons Attribution License, which permits unrestricted use, distribution, and reproduction in any medium, provided the original author and source are credited.

\begin{abstract}
Class I homeobox genes are a family of transcription factors involved in human development, in the regulation of the cell memory program. Several HOX genes control the normal hematopoietic processes; recent evidence has demonstrated that deregulation of HOX genes plays a crucial role in the leukemogenesis and in many solid tumors mainly by means, the regulation of cell proliferation, cell death, metastasis and DNA repair.
\end{abstract}

\section{Keywords: HOX; Cancer; Hematopoiesis}

\section{HOX Genes}

The homeobox genes are a transcription factor family; they are divided in several classes. Class I homeobox genes (HOX in mice and HOX in humans), are 39 transcription factors, mainly involved in the regulation of embryonic development program; The HOX genes are characterized by a sequence of 183 nucleotides encoding a homeodomain of 61 amino acid that binds to DNA, as a biological gripper, activating or repressing specific genes $[1,2]$.

The HOX genes are organized into four chromosomal clusters or loci (HOXA Chr 7p15.3, HOXB Chr 17q21.3, HOXC Chr 12q13.3 and HOXD Chr 2q31), each having 9-11 genes.

Based on the sequence similarity and their position into the locus, the corresponding genes, of the four clusters, can be aligned with each other in 13 paralogous groups (Figure 1) [3].

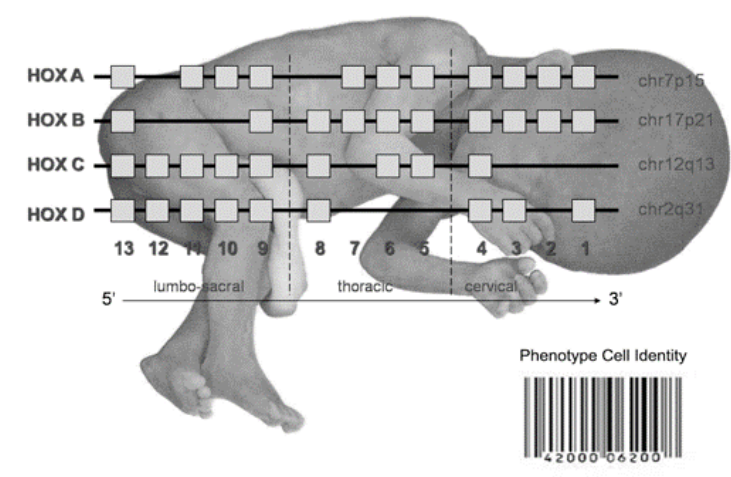

Figure 1: Schematic representation of the HOX gene network (see text for details).

HOX gene expression controls the identity of several regions along the body axis according to the rules of temporal and spatial colinearity, with 3' HOX genes (retinoic acid responsive) expressed early in development and controlling anterior regions, followed by progressively more 5' genes (Fibroblast Growth Factor responsive) expressed later and controlling more posterior regions [4,5]. The HOX gene network, the most repeat-poor regions of the human genome [6], is also expressed in normal adult human organs [7]. Homeobox and HOX genes appear to regulate normal development, phenotype cell identity $[8,9]$ cell differentiation $[10,11]$ and control primary cellular processes, as proven by the description of congenital [12], somatic [13], metabolic [14] and neoplastic alterations [15,16] involving these genes. In addition to their role as transcriptional regulators, new crucial functions have recently been ascribed to HOX genes and homeoproteins mostly related to their interaction with miRNAs and ncRNAs to guarantee transcription and translation of specific RNA transcripts $[17,18]$.

The HOX network is active in adult human tissues and organs, controls the spatial-temporal generation of biological structure expected during embryonic development and regulates the cell memory program [4].

\section{Cell Memory Program}

The memory program contains much information crucial to the cell life cycle: where the daughter cell will be located; what phenotype identity will acquire; when both these properties will be express; the number of cell division the daughter cell will be able to perform; and when, if ever, will they go through apoptosis [19] (Figure 2).

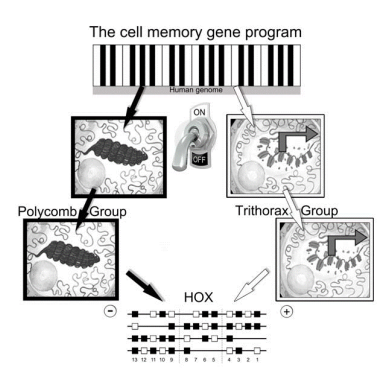

Figure 2: The cell memory gene program (see text for details).

The cellular memory was regulated by three gene families: the Polycomb genes, able to block DNA-chromatin interaction leading to 
HOX gene silencing. The Trithorax genes, able to induce mRNA transcription through an open configuration of DNA-chromatin interaction and leading to HOX gene activation; finally the HOX genes involved in the orchestration of phenotype specific gene program mostly through the fine regulation of mRNA transcription [4].

\section{Homeobox Genes and Cancer}

The HOX network regulates multiple cellular processes, such as acquisition and maintenance of spatial and temporal cell allocation, cell identity, control of cell growth and proliferation, cell-cell communication, anteroposterior patterning during embryonic development, and organogenesis. Most of these functions were established in cooperation with other molecules and factors. So far, several mutations of homeobox genes have been described, that lead to dysregulation of any of these functions and association with different human diseases including different types of cancers [15].

Cancer can be a consequence of the alterations in specific steps of each of the processes concerning cell growth, proliferation and differentiation, cell communication and apoptotic pathway. There is a connection between embryonic development and cancer [20]. An increased incidence of paediatric cancers and stillbirths is found in individuals born with a human cervical rib, a congenital anomaly observed also in transgenic mice with mutation in homeobox genes. Thus, homeobox genes appear to regulate normal development and normal and abnormal cell proliferation [21].

\section{Homeobox Genes in Solid Tumors}

Major abnormalities of homeobox gene expression have been identified in many primary solid tumors (kidney, colon, small cell lung cancer). Three categories of homeobox gene expression in malignant cells have been defined by Abate-Shen [22]. An experiment was made to detect the expression of HOX-A7, HOX-C5 and HOX-D13 in normal and malignant lung tissue, which had been found earlier in most of the SCLC cell lines, but not in adult lungs [23]. There were samples from tumors taken from smokers and samples from normal lung tissue mainly from non-smokers. In the analysis of the noncancer tissues from the non-smokers, no expression of HOX-A7, HOX-C5 and HOX-D13 was detected. Only one sample of the normal lung tissue, from a smoker, expressed HOX-C5. HOX-C5 and HOXD13 were also expressed in most of the tumor samples. HOX-A7 was expressed in all five tumors tissues in which it was measured. In the normal lung parenchyma taken from sites distant from tumors only a few expressed HOX-C5 and HOX-D13, but HOX-A7 was expressed in 3 of 5 samples. This increased expression may be an early pretransformation event, occurring in carcinogen-exposed, but nontransformed cells. The HOX gene expression has been linked to apoptosis: lack of expression of HOX-A5 in breast cancer may be responsible for loss of expression of p53 [23].

In melanoma (Me 665/2) cells, it was possible to separate clonal populations regarding their metastatic potential based on their pattern of expression of HOX-C, integrins and ICAM-1 genes. In the clones with high levels of integrins and ICAM-1, there was no detectable expression of the genes of HOM-C, whereas in clones with low levels of integrins and ICAM-1, HOX-C genes (HOX-C10, HOX-C11 and HOX-C13) were highly expressed [24].

It has recently been demonstrated the involvement of homeobox genes in evolution of colon cancer [24]. Cdx1 and $\mathrm{Cdx} 2$ genes are involved in differentiation of intestinal epithelium and regulate the early stages of colon embryonic development [25]. The expression of isolated HOX genes (HOX B7 and HOX C6), it was studied, in vitro, during the $\mathrm{CaCo} 2$ cell differentiation [26].

Recently it has been demonstrated that HOX genes are involved in the pathogenesis of cancer. A large number of HOX genes are altered in several tumors; HOXA7 e HOXD13 in the lung cancer [27], HOXC4 E HOXC8 in the prostate cancer [28], HOXB7 in ovarian and breast cancer [29], HOXA10 in endometrial cancer [28], HOXA5 in breast cancer [30]. The reduction of HOXD10 in epithelial cells, is related to an increase of malignancy [31]

\section{Homeobox Genes in Haematopiesis}

Leukemias, as myeloid leukemia (AML) and acute lymphoid leukemia (ALL) are characterized by deregulation of HOX genes [16,32-34]. Homeobox genes are able to induce translocation and fusion in hematologic neoplasia [35,36,37]. The translocation of $\mathrm{t}$ $(7 ; 11)(\mathrm{p} 15, \mathrm{p} 15)$ in acute myeloid leukemia, was determined by a fusion of HOXA9 protein with amino terminus region NUP98 [13,38]. Hematological neoplasia was due to HOX gene deregulation, with a strong collaboration with other gems. In details HOXA9 and MEIS-1 genes were specifically expressed in AML and this gene is highly correlated with poor prognosis in AML [39-42]. The HOXA locus was always expressed in T-cells acute lymphocytic leukemia sample [43-44]. Moreover, HOXA cluster was upregulated in mixed-lineage leukemia (MLL), suggesting that HOXA locus was highly involved in these leukemias [45], whereas HOXA9, HOXA10, HOXB3, HOXB6 and HOX B8, were able to induce leukemia latency. Furthermore, the co-upregulation of genes plays a crucial role in the progression of leukemia. For example MEIS-1 was an interactor of many HOX genes, mainly with HOXB4, inducing the onset of pathology [46-48]. Finally, alteration of HOX gene network was crucial in several leukemic pathologies.

\section{Conclusions}

On the basis of data present in literature, we could hypotize that homeobox genes act as a system to decode several cancer types and also this gene play an important role in oncogenesis and may have a high value in clinical diagnostics.

In conclusion, we could consider HOX gene network crucial not only for clinical diagnostics in cancer, but also for characterizing all human cell phenotype. Considering the role of Class I Homeobox genes in the epigenetic control of human cell memory program, cell phenotypes, HOX cluster could be used as "the Rosetta stone" of human cell biology.

\section{References}

1. Graham A, Papalopulu N, Krumlauf R (1989) The murine and Drosophila homeobox gene complexes have common features of organization and expression. Cell 57: 367-378.

2. Krumlauf R (1994) HOX genes in vertebrate development. Cell 78: 191-201.

3. Apiou F, Flagiello D, Cillo C, Malfoy B, Poupon MF, et al. (1996) Fine mapping of human HOX gene clusters. Cytogenet Cell Genet 73: 114-115.

4. Procino A, Cillo C (2013) The HOX genes network in metabolic diseases. Cell Biol Int 37: 1145-1148.

5. Dekker EJ, Pannese M, Houtzager E, Timmermans A, Boncinelli E, et al. (1992) Xenopus HOX-2 genes are expressed sequentially after the onset 
of gastrulation and are differentially inducible by retinoic acid. Dev Suppl.

6. Lander ES, Linton LM, Birren B, Nusbaum C, Zody MC, et al. (2001) Initial sequencing and analysis of the human genome. Nature 409: $860-921$.

7. Cillo C (1994) HOX genes in human cancers. Invasion Metastasis 14: 38-49.

8. García-Bellido A (1975) Genetic control of wing disc development in Drosophila. Ciba Found Symp 0: 161-182.

9. Cillo C, Cantile M, Faiella A, Boncinelli E (2001) Homeobox genes in normal and malignant cells. J Cell Physiol 188: 161-169.

10. Magli MC, Barba P, Celetti A, De Vita G, Cillo C, et al. (1991) Coordinate regulation of HOX genes in human hematopoietic cells. Proc Natl Acad Sci U S A 88: 6348-6352.

11. Cantile M, Procino A, D'Armiento M, Cindolo L, Cillo C (2003) HOX gene network is involved in the transcriptional regulation of in vivo human adipogenesis. J Cell Physiol 194: 225-236.

12. Mortlock DP, Innis JW (1997) Mutation of HOXA13 in hand-footgenital syndrome. Nat Genet 15: 179-180.

13. Nakamura T, Largaespada DA, Lee MP, Johnson LA, Ohyashiki K, et al. (1996) Fusion of the nucleoporin gene NUP98 to HOXA9 by the chromosome translocation $\mathrm{t}(7 ; 11)(\mathrm{p} 15 ; \mathrm{p} 15)$ in human myeloid leukaemia. Nat Genet 12: 154-158.

14. Ferber S, Halkin A, Cohen H, Ber I, Einav Y, et al. (2000) Pancreatic and duodenal homeobox gene 1 induces expression of insulin genes in liver and ameliorates streptozotocin-induced hyperglycemia. Nat Med 6: 568-572.

15. Cillo C, Faiella A, Cantile M, Boncinelli E (1999) Homeobox genes and cancer. Exp Cell Res 248: 1-9.

16. Abate-Shen C (2002) Deregulated homeobox gene expression in cancer: cause or consequence? Nat Rev Cancer 2: 777-785.

17. Cobb J, Duboule D (2004) Tracing microRNA patterns in mice. Nat Genet 36: 1033-1034.

18. Rinn JL, Kertesz M, Wang JK, Squazzo SL, Xu X, et al. (2007) Functional demarcation of active and silent chromatin domains in human HOX loci by noncoding RNAs. Cell 129: 1311-1323.

19. Bantignies F, Cavalli G (2006) Cellular memory and dynamic regulation of polycomb group proteins. Curr Opin Cell Biol 18: 275-283.

20. Ferrier DE, Holland PW (2001) Ancient origin of the HOX gene cluster. Nat Rev Genet 2: 33-38.

21. Grier DG, Thompson A, Kwasniewska A, McGonigle GJ, Halliday HL, et al. (2005) The pathophysiology of HOX genes and their role in cancer. J Pathol 205: 154-171.

22. Lechner JF, Wang Y, Siddiq F, Fugaro JM, Wali A, et al. (2002) Human lung cancer cells and tissues partially recapitulate the homeobox gene expression profile of embryonic lung. Lung Cancer 37: 41-47.

23. Raman V, Martensen SA, Reisman D, Evron E, Odenwald WF, et al. (2000) Compromised HOXA5 function can limit p53 expression in human breast tumours. Nature 405: 974-978.

24. De Vita G, Barba P, Odartchenko N, Givel JC, Freschi G, et al. (1993) Expression of homeobox-containing genes in primary and metastatic colorectal cancer. Eur J Cancer 29A: 887-893.

25. Duluc I, Lorentz O, Fritsch C, Leberquier C, Kedinger M, et al. (1997) Changing intestinal connective tissue interactions alters homeobox gene expression in epithelial cells. J Cell Sci $110: 1317-1324$

26. Sebastio G, D'Esposito M, Montanucci M, Simeone A, Auricchio S, et al. (1987) Modulated expression of human homeobox genes in differentiating intestinal cells. Biochem Biophys Res Commun 146: 751-756.

27. Lechner JF, Fugaro JM, Wong Y, Pass HI, Harris CC, et al. (2001) Perspective: cell differentiation theory may advance early detection of and therapy for lung cancer. Radiat Res 155: 235-238.

28. Miller GJ, Miller HL, van Bokhoven A, Lambert JR, Werahera PN, et al. (2003) Aberrant HOXC expression accompanies the malignant phenotype in human prostate. Cancer Res 63: 5879-5888.
29. Naora H, Yang YQ, Montz FJ, Seidman JD, Kurman RJ, et al. (2001) serologically identified tumor antigen encoded by a homeobox gene promotes growth of ovarian epithelial. Proct Natl Acd Sci Mar 27; 98(7): 4060-5

30. Chen H, Chung S, Sukumar S (2004) HOXA5-induced apoptosis in breast cancer cells is mediated by caspases 2 and 8 . Mol Cell Biol 24: 924-935.

31. Carrio M, Arderiu G, Myers C, Boudreau NJ (2005) Homeobox D10 induces phenotypic reversion of breast tumor cells in a threedimensional culture model. Cancer Res 65: 7177-7185.

32. Samuel S, Naora H (2005) Homeobox gene expression in cancer: insights from developmental regulation and deregulation. Eur J Cancer 41: 2428-2437.

33. Shah N, Sukumar S (2010) The HOX genes and their roles in oncogenesis. Nat Rev Cancer 10: 361-371.

34. Argiropoulos B, Humphries RK (2007) HOX genes in hematopoiesis and leukemogenesis. Oncogene 26: 6766-6776.

35. Borrow J, Shearman AM, Stanton VP Jr, Becher R, Collins T, et al. (1996) The $t(7 ; 11)(p 15 ; p 15)$ translocation in acute myeloid leukaemia fuses the genes for nucleoporin NUP98 and class I homeoprotein HOXA9. Nat Genet 12: 159-167.

36. Golub TR, Slonim DK, Tamayo P, Huard C, Gaasenbeek M, et al. (1999) Molecular classification of cancer: class discovery and class prediction by gene expression monitoring. Science 286: 531-537.

37. Kawagoe H, Humphries RK, Blair A, Sutherland HJ, Hogge DE (1999) Expression of HOX genes, HOX cofactors, and MLL in phenotypically and functionally defined subpopulations of leukemic and normal human hematopoietic cells. Leukemia 13: 687-698.

38. Lawrence HJ, Sauvageau G, Humphries RK, Largman C (1996) The role of HOX homeobox genes in normal and leukemic hematopoiesis. Stem Cells 14: 281-291.

39. Drabkin HA, Parsy C, Ferguson K, Guilhot F, Lacotte L, et al. (2002) Quantitative HOX expression in chromosomally defined subsets of acute myelogenous leukemia. Leukemia 16: 186-195.

40. Speleman F, Cauwelier B, Dastugue N, Cools J, Verhasselt B, et al. (2005) A new recurrent inversion, $\operatorname{inv}(7)(\mathrm{p} 15 \mathrm{q} 34)$, leads to transcriptional activation of HOXA10 and HOXA11 in a subset of T-cell acute lymphoblastic leukemias. Leukemia 19: 358-366.

41. Cauwelier B, Cave H, Gervais C, Lessard M, Barin C, Perot C et al (2007). Clinical, cytogenetic and molecular characteristics of 14 TALL patients carrying the TCRbeta-HOXA rearrangement: a study of the Groupe Francophone de Cytogenetique Hematologique. Leukemia 21: 121-128.

42. Soulier J, Clappier E, Cayuela JM, Regnault A, García-Peydró M, et al. (2005) HOXA genes are included in genetic and biologic networks defining human acute T-cell leukemia (T-ALL). Blood 106: 274-286.

43. Sauvageau G, Thorsteinsdottir U, Eaves CJ, Lawrence HJ, Largman C, et al. (1995) Overexpression of HOXB4 in hematopoietic cells causes the selective expansion of more primitive populations in vitro and in vivo. Genes Dev 9: 1753-1765.

44. Thorsteinsdottir U, Sauvageau G, Humphries RK (1999) Enhanced in vivo regenerative potential of HOXB4-transduced hematopoietic stem cells with regulation of their pool size. Blood 94: 2605-2612.

45. Kroon E, Krosl J, Thorsteinsdottir U, Baban S, Buchberg AM, et al. (1998) HOXa9 transforms primary bone marrow cells through specific collaboration with Meisla but not Pbx1b. EMBO J 17: 3714-3725.

46. Fischbach NA, Rozenfeld S, Shen W, Fong S, Chrobak D, et al. (2005) HOXB6 overexpression in murine bone marrow immortalizes a myelomonocytic precursor in vitro and causes hematopoietic stem cell expansion and acute myeloid leukemia in vivo. Blood 105: 1456-1466.

47. Schuettengruber B, Chourrout D, Vervoort M, Leblanc B, Cavalli G (2007) Genome regulation by polycomb and trithorax proteins. Cell 128: 735-745. 
Citation: Procino A (2014) HOX Genes and Oncogenesis. J Mol Genet Med 8: 134. doi:10.4172/1747-0862.1000134

Page 4 of 4

48. Ringrose L, Paro R (2004) Epigenetic regulation of cellular memory by the Polycomb and Trithorax group proteins. Annu Rev Genet 38: 413-443. 